\title{
Migration channels produced by laser ablation for substrate endothelialization
}

\author{
R. MAJOR ${ }^{1 *}$, K. MAKSYMOW ${ }^{1}$, J. MARCZAK ${ }^{2}$, J.M. LACKNER ${ }^{3}$, M. KOT ${ }^{4}$, and B. MAJOR ${ }^{1}$ \\ ${ }^{1}$ Institute of Metallurgy and Materials Science of Polish Academy of Sciences, 25 Reymonta St., 30-059 Cracow, Poland \\ ${ }^{2}$ Institute of Optoelectronics, Military University of Technology, 2 Kaliskiego St., 00-908 Warsaw, Poland \\ ${ }^{3}$ Joanneum Research Forschungs-GmbH, Materials - Functional Surfaces, 94 Leobner Strasse, Leoben, A-8712 Niklasdorf, Austria \\ ${ }^{4}$ Faculty of Mechanical Engineering and Robotics, AGH University of Science and Technology, \\ 30 Mickiewicza Ave., 30-059 Cracow, Poland
}

\begin{abstract}
Seeding of cells on functional, biocompatible scaffolds is a crucial step in achievement the desired engineered tissue. In the present study, a pulsed laser modification onto inorganic substrate was made to promote endothelium cells migration and spread. Presented scaffolds were fabricated on carbon and titanium based coatings. Fabricated films provided very good mechanical properties together with a chemical stability preservation. The substrate modification consisted of grid-like template fabrication of micrometer size meshes. The microstructure analysis of laser traces revealed the grain size increase in the zone of laser beam interaction, which exerts an influence on a surface topography. Endothelium cells locomotion was observed within 10 day time period. As a result it was shown that the modified area enhanced cells adhesion with a preferred static behavior. The performed research work improved our understanding on the pulsed laser ablation process and template size influence on cells spatial arrangement. It constituted an important step towards fabrication of inorganic, biocompatible scaffolds for successful substrate endothelialization.
\end{abstract}

Key words: inorganic coatings, pulsed laser ablation, tissue scaffold, endothelial cells migration.

\section{Introduction}

Endothelial cells play a principal role in a complex mechanism evolved to provide balance in a circulatory system [1]. The endothelium layer acts as a dynamic interface which actively regulates inflammation, thrombosis and fibrinolysis. Where blood is in contact with an artificial surface, a number of undesired reactions may occur. The endothelium is commonly known as the most biocompatible for contact with streaming blood. Its combination with biomaterials can be applied in order to prevent thrombotic and inflammatory reactions and improve artificial device integration [2-4]. Producing confluent endothelial layers which cover full of the surface became the important task at which experimental efforts should be concentrated.

A local environment creates a crucial influence on cells behavior, shape, alignment and orientation. The chemical composition and topography of substrate affect cellular functions, like: adhesion, growth, locomotion, gene expression and apoptosis. Control of the biological environment through suitable scaffold properties is the essential task for tissue engineering [5]. The biocompatibility and mechanical strength support tissue growing and contracting. Proper physical and chemical properties promote cell adhesion and cell growth. Channels and ridges in a surface structure guide cells migration and orientation, providing the healthy tissue organization and mechanical strength [6].

At present, the most popular techniques for 3D scaffold preparation are adapted from microelectronics indus- try. They are photolithography, soft lithography, direct writing and laser ablation. Material and resolution constrains as well as large costs are not only drawbacks for photolithography. Direct writing techniques, like, deep pen lithography and elastomeric stamp pattering overcome some limitations but still they are not suitable for larger area modification [7-9]. The method of laser ablation was used in the presented study. Advantages of this approach are as follow: high resolution (down to $25 \mathrm{~nm} \mathrm{[10]),} \mathrm{non-contact} \mathrm{in-}$ teraction and applicability to any substrate. The thermal and mechanical propagation occur during irradiation by nanosecond and longer laser pulses, causing melting and vaporization far from the absorption site and, re-solidification of the melt zone [11].

Basically, inorganic coatings from metal oxides, nitrides and carbon based materials have already the clinical application. Generally, those coatings exhibit high inertness, mechanical and chemical stability. This predestines them as primarily passive hemocompatible coatings. Thus in our research, coating materials from this group were selected.

The goal of this study was the laser beam topography modification of biomaterials surface towards controlled HUVEC (Human Umbilical Vein Endothelial Cells) migration. Presented results have a cognitive character in the way of cells behavior dependent on substrate modification. This strategy led to generate macroscopic grafts covered by endothelium layer for contact with circulating blood and application in number of biomedical devices.

*e-mail: nmrmajor@imim-pan.krakow.pl 


\section{Materials and methods of examination}

2.1. Cover type selection. Titanium dioxide $\left(\mathrm{TiO}_{2}\right)$, titanium carbonitride $(\mathrm{Ti}(\mathrm{C}, \mathrm{N}))$, diamond like carbon (DLC, a-C:H) and silicon doped diamond like carbon $(\mathrm{a}-\mathrm{C}: \mathrm{H}: \mathrm{Si})$ as a top layer material were examined towards biocompatibility and tribological properties. Films were fabricated by means of surface modification dedicated to the blood - material interaction purpose. Variable energetic conditions were attained by DC and pulsed DC magnetron sputtering with increasing medium plasma energy, pulsed laser deposition (PLD) and ion-source plasma activated chemical vapor deposition PACVD. Titanium dioxide and titanium carbo-nitride films were deposited by hybrid PLD (Nd;YAG laser, $1064 \mathrm{~nm}$ wavelength) from pure Ti source $(>99 \%)$ assisted with unbalanced DC magnetron sputtering in argon-nitride and argon-oxide atmospheres. DLC and Si doped DLC layers were obtained by pulsed DC magnetron sputtering in inert argon conditions, Si-doping from silicon target in $\mathrm{C}_{2} \mathrm{H}_{2}$ atmosphere. Films growth was achieved in a range between room temperature and $50^{\circ} \mathrm{C}$. The detailed description of the method is given in literature $[12,13]$. There were applied industrially up-scaled coating processes at Joanneum Research Forschungs - GmbH in Leoben, Austria.

2.2. Migration channels preparation. Migration channels were prepared by the laser ablation. Thin, nanometer scale parts of the coating of $50 \mathrm{~nm}$ were removed in the half deepness of the thickness. The process of ablation occurs during the laser pulse by an interaction between laser radiation (absorption and scatter) and the ejected material in the liquid form. During treatment of material surface with a pulsed laser radiation of sufficient energy density over time (power density), the following phenomena take place: absorption of radiation and thermal or photochemical effects. The desired reflectance needs low radiation. Hence, excitation requires a large area of the laser beams with intensities and small depth of absorption of laser radiation (Fig. 1). The thickness of the evaporated layer depends on material properties like: optical, thermal and laser beam parameters, wavelength, power density, laser pulse duration time.

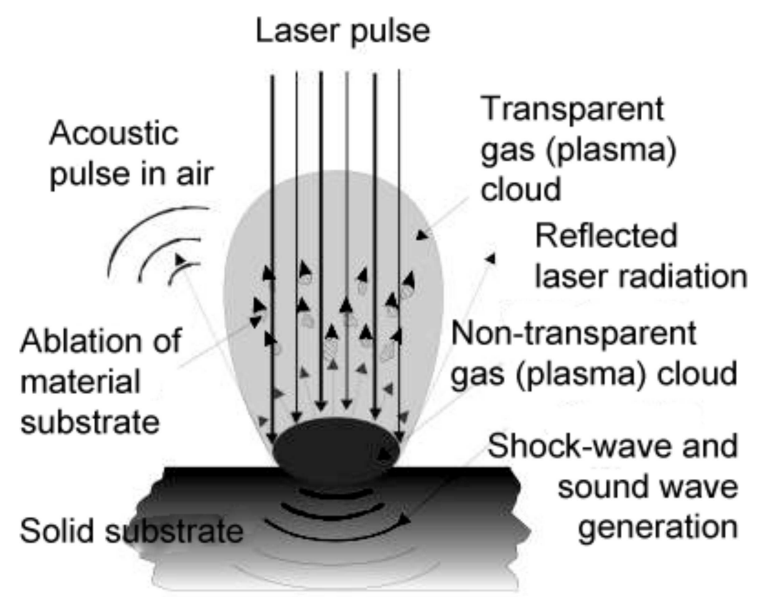

Fig. 1. Interaction mechanism and phenomena of pulsed laser radiation with a solid
Process parameters were properly matched to enable execution of the half of the layer thickness. Orders of periodic wells were formed in channels and they were put on the surface in a square like shape.

\subsection{Materials characterization. $X$-ray diffraction analysis.} The tests were performed using an X-ray diffractometer Bruker D-8 with filtered radiation $\mathrm{Cu} \mathrm{K} \alpha$, beam system: optics, "PolyCap" with $0,1 \mathrm{~mm}$ collimator was applied. Phase identification was based on experimental data recorded by an X-ray diffraction technique in symmetric geometry (detector scan), which enable to analyze the material with the constant incident beam penetration depth. EVA ICCD software and database was used for the phase identification.

Transmission Electron Microscopy. An analysis of the structure of migration channels was performed using transmission electron microscopy (TEM). Thin foils for the TEM analysis were prepared on cross-section from the border between the migration channel and not modified surface. The platinum mask was used to distinguish the proper area for examination. Samples were made using the focused ion beam method (FIB) (Fig. 2) and area subjected to examination were marked on the SEM image.

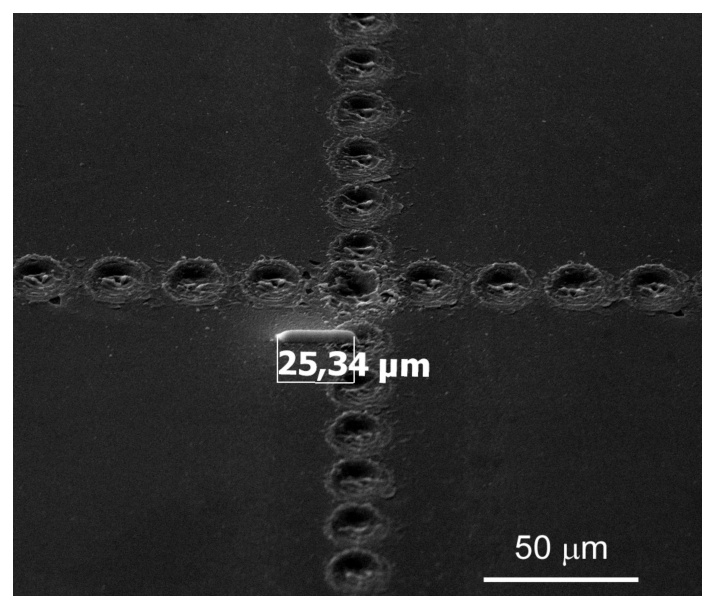

Fig. 2. Microstructure SEM; thin foil preparation using FIB from a place chosen on a migration channel

2.4. Biological characterization. The modified area was examined in contact with endothelium cell of HUVEC culture. It was kept in the incubation conditions: 5\% CO2 100\% humidity, $37^{\circ} \mathrm{C}$ for four days. After this time cells were fixed in $4 \%$ solution of paraform(aldehyde). Mitochondria, cytoskeletons and nuclei were stained with green carbocyanine-based MitoTracker Green, Alexa Fluor 488 and DAPI, respectively, and observed under a confocal microscope LSM 5 EXCITER. Transmission Electron Microscopy (TEM) measurements enabled detail analysis of the microstructure of the substrate.

\section{Results}

3.1. Mechanical properties of coatings. In order to investigate the crucial material features influencing the cells-material 


\section{Migration channels produced by laser ablation for substrate endothelialization}

interaction, a detailed research work was conducted. Tribological tests were used for selection of the most adequate material which has the best cohesion, the highest adhesion to the substrate, the lowest friction and a good biocompatibility. In order to determine sample properties a scratch test with Rockwell $\mathrm{C}$ indenter (radius $=200 \mu \mathrm{m}$ ) and with sample pass velocity $5 \mathrm{~mm} / \mathrm{min}$ was performed. It inserts high stress with low loads inside the material. DLC cover reveals the first cracks with $0.2 \mathrm{~N}$ load (Table 1). A film wear occurs with load $0.4 \mathrm{~N}$ (Table 2). Doping DLC cover with silicon atoms worsen the film adhesion, it starts to peel with load $0.1 \mathrm{~N}$ (Table 2). The best properties among the measured films has $\mathrm{TiO}_{2}$. There has not been observed destruction of adhesion, load $0.22 \mathrm{~N}$ results in first cracks. Increase of load till $1.3 \mathrm{~N}$ caused crushing the silicon substrate for all systems.

Table 1

Film material dependence on load causing cohesion cracks (Lc1)

\begin{tabular}{cc}
\hline \hline Film material & Lc1 $[\mathrm{N}]$ \\
\hline $\mathrm{DLC}$ & 0.2 \\
\hline $\mathrm{Si}-\mathrm{DLC}$ & 0.1 \\
\hline $\mathrm{TiO}_{2}$ & 0.22 \\
\hline
\end{tabular}

Table 2

Film material dependence on adhesion destruction (Lc2)

\begin{tabular}{cc}
\hline \hline Film material & Lc2 $[\mathrm{N}]$ \\
\hline $\mathrm{DLC}$ & 0.4 \\
\hline $\mathrm{Si}-\mathrm{DLC}$ & 0.1 \\
\hline $\mathrm{TiO}_{2}$ & 0.7 \\
\hline
\end{tabular}

All coatings being in contact with the diamond indenter reveal a low friction coeffcient (Fig. 3). Based on scratch test results and tribological measurements, the titanium dioxide layer was selected for further analysis due to the best adhesion, low wear and low friction.

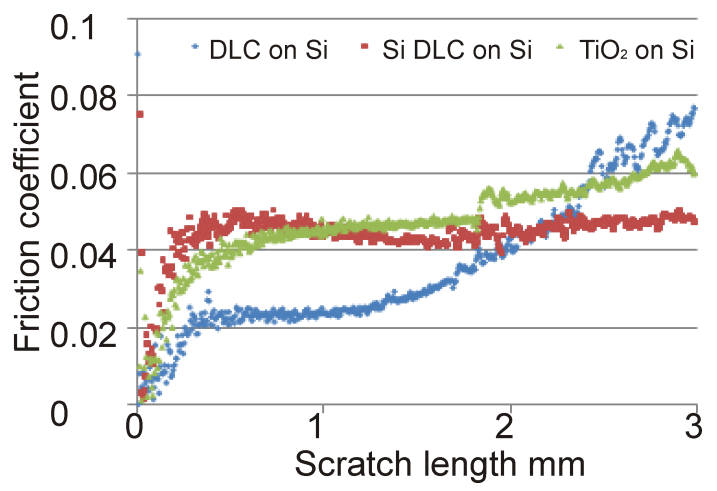

Fig. 3. Friction coefficient dependence on scratch length for different film material

\subsection{Channels fabrication and properties. Substrate topog-} raphy and morphology. A single laser pulse interaction with a flat surface resulted in a crater formation. Its diameter was approximately equal $21 \mu \mathrm{m}$ and depth $5 \mu \mathrm{m}$ (Fig. 4). Parts of the material produced in ablation process were propagated and deposited on the surface because of the re-sputtering effect. As a result, the structure of the surface next to the craters has been changed (Fig. 5).

a)

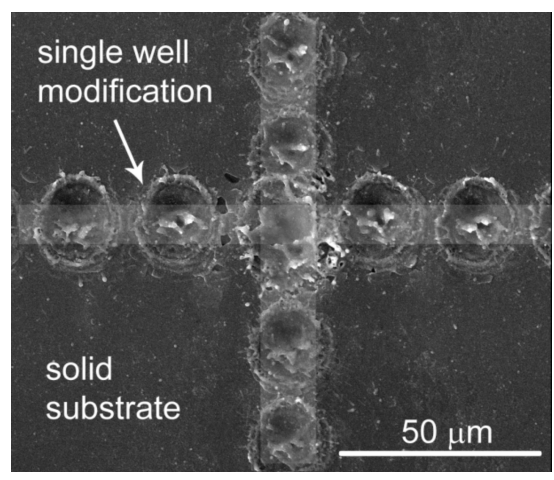

b)

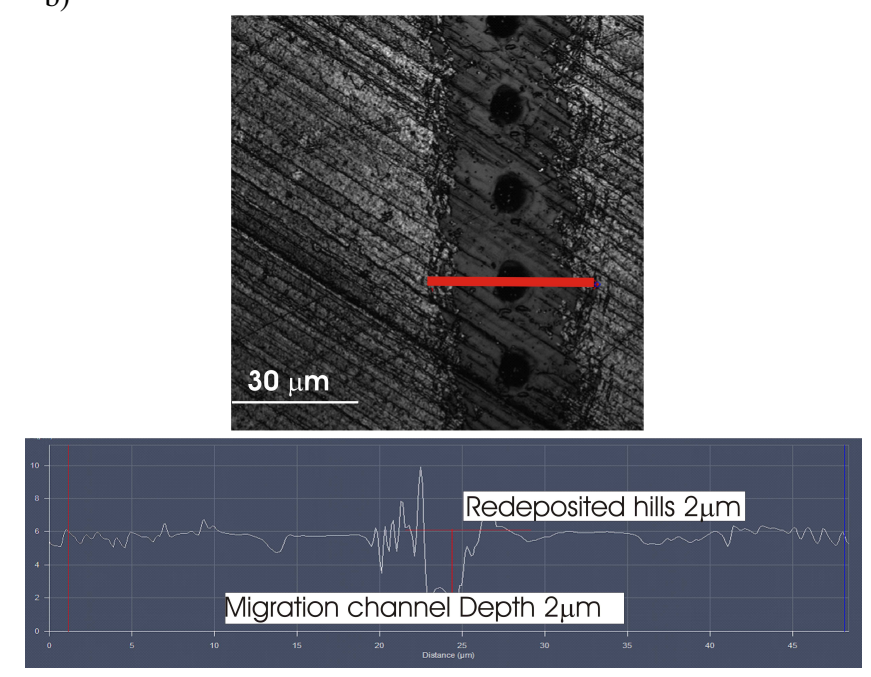

Fig. 4. Surface modification by direct laser pulse ablation leads to create a special ordered template in micro-scale (a), single cross section through well made by laser pulse (b)
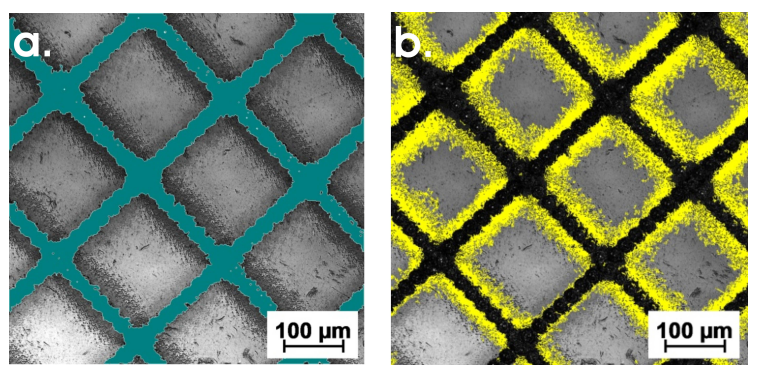

Fig. 5. Grid made by periodically fabricated micrometer size wells (a) blue color and area covered with re-sputtered material (b) yellow color created during irradiation process

Surface modification size. The laser ablation enables to fabricate well organized craters which established grid like template on the substrate. One square mesh size is equal approximately to $200 \mu \mathrm{m}$ (Fig. 6). Three types of channels were prepared and differences were associated with their deepness. The channel character would influence the stress accumulation. The deepest crater was selected for the further examination of cell migration. 


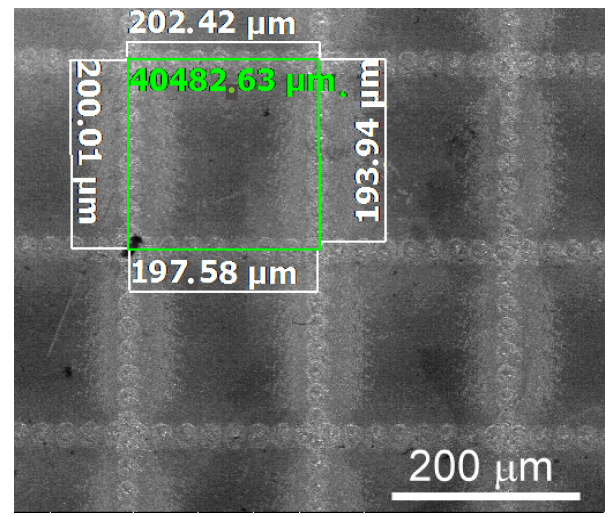

Fig. 6. Scanning Electron Microscopy image of examined surface with fabricated migration channels

Phase analysis and residual stress. The influence of the surface modification was analyzed using an X-ray diffraction technique. The channel formation using the ablation method could significantly influence on the cellular behavior. The phase analysis revealed more crystallized structure in comparison to the as deposited one. Differences in the diffraction peak height were associated with differences in the crystallized stage. The peak broadening illustrated the crystallite size and the observed differences between channels were stated. They are presented in Table 3 .

Table 3

Crystalline size

\begin{tabular}{cc}
\hline \hline Place & Crystalline size $\AA^{\circ}$ \\
\hline As deposited surface & 96.4 \\
\hline Channel 1 (deepness high) & 116.3 \\
\hline Channel 2 (deepness middle) & 96.0 \\
\hline Channel 3 (deepness low) & 98.8 \\
\hline
\end{tabular}

$\mathrm{X}$-ray residual stress measurements revealed that the highest values of the residual stress were stated for the not treated coating (as deposited) Table 4. Surface modification introduced the reduction of the stress in the structure. For the channel 2, the total residual stress deduction was possible. For the channel 1 high stress reduction was observed. The error was close to the value of the stress thus the measurements were not possible to perform. The surface modification with stress annihilation typical for the channel 1 was chosen for the further examination.

Table 4

Residual stress

\begin{tabular}{ccc}
\hline \hline Place & Residual stress MPa & Error \\
\hline As deposited surface & -9156.6 & $+/-478.5$ \\
\hline Channel 1(deepness high) & Not-measurable & $+/-3292.1$ \\
\hline Channel 2(deepness middle) & -3812.5 & $+/-671.7$ \\
\hline Channel 3(deepness low) & -4615.2 & $+/-594.4$ \\
\hline
\end{tabular}

Endothelial cells interaction with fabricated substrate. The fabricated grid template on a silicon wafer covered with $\mathrm{TiO}_{2}$ layer was used as migration channels for endothelial cells of HUVEC culture (Human Ambilical Vein Endothelial
Cells). External signals from the substrate (e.g. topography, physicochemical structure diversity) may induce an assembly of cytoskeleton through actin polymerization which could influence the cell locomotion. The cell migration undergoes series of characteristic events: extension of one or more lamellipodia (mobile edge of the cell) from the leading edge, adhesion to the substrate, forward movement, retracting of the cell body (Fig. 7) [1]. Cells fixed during the movement should be elongated and flatten as distinct from a stationery state.

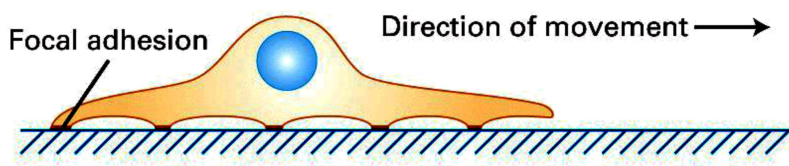

1 Extension

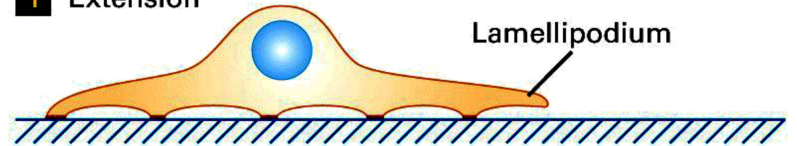

Adhesion

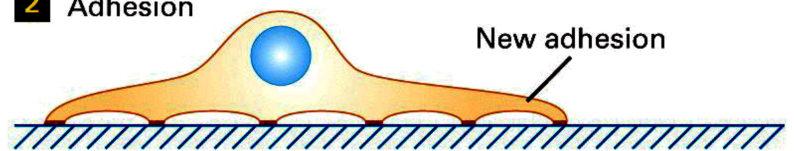

Translocation

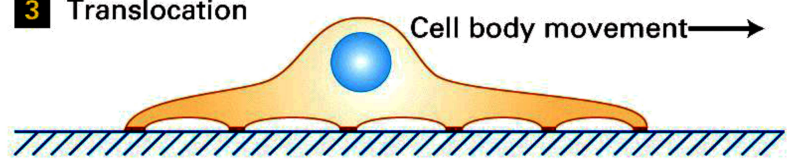

De-adhesion

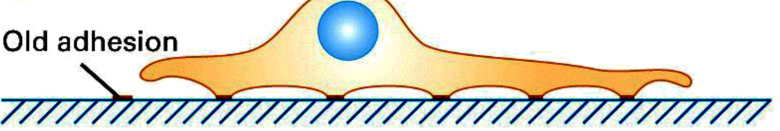

Fig. 7. Steps in cell movement on a substrate

Confocal microscope observations showed the relation between a surface topography and cells preferences during migration on the surface. On flat surface the locomotion was not oriented Fig. 8a. It was visualized that the polymerized actin forms lamelipodia and influence their elongation (Fig. 9). Cells were elongated towards the evaporated part of the surface. It seemed that cells in the well had static shape and would not move to the other place Fig. $8 \mathrm{~b}$.
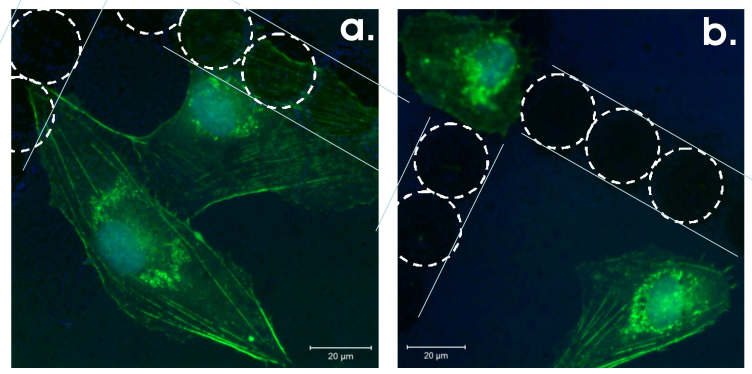

Fig. 8. HUVEC behavior on modified and unmodified area of the substrate. Cells migration on flat surface without preferred direction $\mathrm{a}$ and passive behavior inside the channel $\mathrm{b}$ 
Migration channels produced by laser ablation for substrate endothelialization

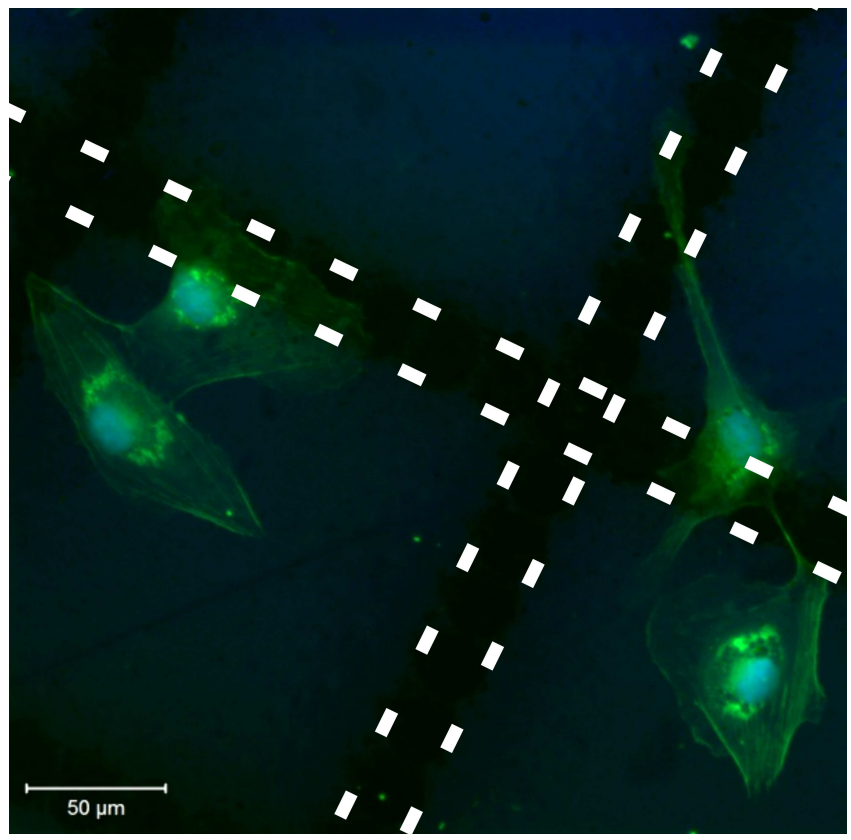

Fig. 9. Endothelium cells behavior in area next to the migration channel

3.3. Material structure analysis in microscale; transmission electron microscopy (TEM). The X-ray phase analysis revealed that composition mostly contain titanium oxide phase. Characteristic shape of diffraction pattern confirmed amorphous structure or very fine crystals.

Selected area electron diffraction (SAED) pattern revealed the change of the crystal size (Fig. 10). The ring shape electron diffraction pattern, typical for nanostructures, was observed for as deposited material. The crystallites of the modified surface revealed a bigger size. This was confirmed by the spot like shape of the SAED analysis. TEM analysis exhibits micro-scale inhomogeneity in the migration channel microstructure (Fig. 11). There was no clear and sharp border between not modified and modified part. At the channel border, a formed "hill" originated from the re-sputtering effect. It could influence the cell migration difficulties. On the other side the material removed using the laser ablation seemed to be the most appropriate in this case because of the controlled material removal.
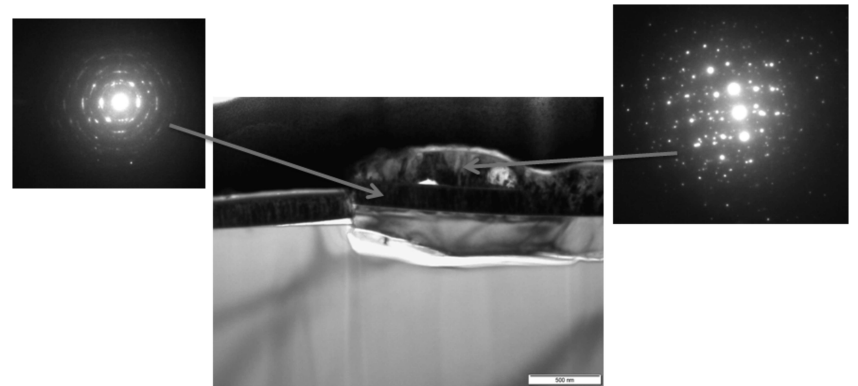

Fig. 10. TEM microstructure of the cross section of the migration channel. Electron diffraction patterns from unmodified (left) and modified (right) area

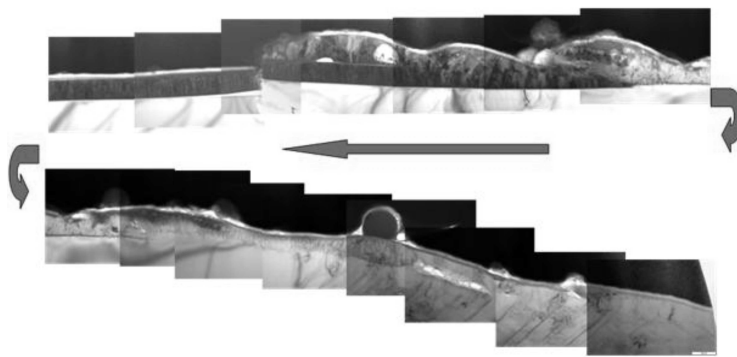

Fig. 11. TEM analysis of migration channel with visible modified and unmodified area

\section{Discussion}

Preparation the appropriate scaffolds for cell growths and controlled cell behavior is the challenging task of the modern biomaterial science. There exist large number of new methods for direct scaffold fabrication. Today's technology of the material preparation enables to have full control over design, fabrication and modeling of chemical and physical properties. Conventional fabrication techniques like gas foaming [15], fiber meshes and bounding [16], phase separation [17], and melt molding [18] used for scaffolds preparation have their limitations. Hence, better control of precision and resolution are needed and should be dynamically developed [19].

Presented in the literature, organic materials applied as the substrate may directly interact with cells, as well as external signals and reveal very good adhesion. Above mentioned materials may be used as appropriate host [20, 21]. However, their long-term application may cause difficulties. In comparison, inorganic materials are chemically stable and neutral for cells. It is hard to compare the data presented in the available literature due to different experimental conditions and methods. The surface topography has been shown to be a key issue in endothelium cells behavior [22, 23]. Endothelial cells (EC) play a significant role in circulatory system [1]. It is not only a passive barrier of flowing blood and the vessel wall but also a highly active tissue with a basic regulatory role in numerous physiological processes. In the field of biomaterial examinations the essential message should result from the homogenous EC layer formation and also its functional conservation [24]. The presence of EC covering on a biomaterial does not prove that physiological balance is achieved. Future studies will be conducted in flow conditions together with a blood-EC-biomaterial in vitro interaction.

The laser ablation technique has many possible applications. It may be successfully applied for cell culture scaffolds preparation [11]. It provides high power with no structure degradation, enables to create desirable 3D topography, what is a crucial factor for cells locomotion steering [25]. The cell seeding density and substrate composition play an important role in the successful endothelialisation process. However, a rare culture is better to measure on single cell migration path and study its behavior for fundamental research. The presented method can be applied to different types of materials and it is possible to modify even large area on a flat surface, but it might be difficult to fabricate migration channels on curved tube-like substrate. 


\section{Conclusions}

The observed effect of cell-substrate interaction enables to draw a general conclusion that endothelium cells migration might be controlled by means of the direct surface modification with the laser beam ablation. Migration channels contribute to a cell behavior. Their real structure in micro-scale reveals grain size growth and topography changes. The future research for a dense cells culture will enable to optimize a scaffold shape. The proposed system could find application for other cells culture type, used in biomedical-engineering and advanced medicine.

Acknowledgements. This research has been supported by the project CardioBioMat Era-NetMNT/15/2009 "Nanostructural materials for implants and cardiovascular biomedical devices" and the Polish-French exchange project: Polonium "New gradient materials fabricated by laser method for blood contact application".

\section{REFERENCES}

[1] H. Lodish, A. Berk, S.L. Zipursky, P. Matsudaira, D. Baltimore, and J. Darnell, Molecular Cell Biology, Willey, London, 2003.

[2] S.K. Williams, "Endothelial cell transplantation", Cell Transplant 4 (4), 401-410 (1995).

[3] S. Kaihara, S. Kim, B.S. Kim, D.J. Mooney, K. Tanaka, and J.P. Vacanti, "Survival and function of rat hepatocytes cocultured with non-parenchymal cells or sinusoidal endothelial cells on biodegradable polymers under flow conditions", $\mathrm{J}$. Pediatr. Surg. 35 (9), 1287-1290 (2000).

[4] T.P. Richardson, M.C. Peters, A.B. Ennett, and D.J. Mooney, "Polymeric system for dual growth factor delivery", Nat. Biotechnol. 19 (11), 1029-1034 (2001).

[5] S. Yang, K. Leong, Z. Du, and C. Chua, "The design of scaffolds for use in tissue engineering, part I, traditional factors", Tissue Eng. 7, 679-689 (2001).

[6] J.H. Wang, F. Jia, T.W. Gilbert, and S.L. Woo, "Cell orientation determines the alignment of cell-produced collagenous matrix", J. Biomech. 36 (1), 97-102 (2003).

[7] R.S. Kane, S. Takayama, E. Ostuni, D.E. Ingber, and G.M. Whitesides, "Patterning proteins and cells using soft lithography", Biomaterials 20, 2363-2376 (1999).

[8] G. Vozzi, C. Flaim, A. Ahluwalia, and S. Bhatia, "Fabrication of plga scaffolds using soft lithography and microsyringe deposition”, Biomaterials 24, 2533-2540 (2003).

[9] R.D. Piner, J. Zhu, F. Xu, S. Hong, and C.A. Mirkin, "Dip-pen nanolithography", Science 283, 661-663 (1999).

[10] A.P. Joglekar, H. Liu, G.J. Spooner, E. Meyhofer, G. Mourou, and A.J. Hunt, "A study of the deterministic character of optical damage by femtosecond laser pulses and applications to nanomachining", Appl. Phys - Lasers Opt. B 77, 25-30 (2003).
[11] Y. Liua, S. Sunb, S. Singhaa, M.R. Chob, and R.J. Gordon, "3D femtosecond laser patterning of collagen for directed cell attachment", Biomaterials 26 (22), 4597-4605 (2005).

[12] B. Major, Ablation and Deposition with the Use of an Impulse Laser, Scientific Publishing House-Akapit, Warsaw, 2002, (in Polish).

[13] J.M. Lackner, Industrially-scaled Hybrid Pulsed Laser Deposition at Room Temperature, Orecop Sc., Cracow, 2005.

[14] T. Burakowski, J. Marczak, and W. Napadlek, "The essence of ablative cleaning materials", Works of Electrotechnical Institute 228, CD-ROM (2006), (in Polish).

[15] D.J. Mooney, D.F. Baldwin, N.P,Suht, J.P. Vacantis, and R. Larger, "Novel approach to fabricate porous sponge of poly(d,1-lactic-co-glycolic acid) without the use of organic solvents", Biomaterials 17, 1417-1422 (1996).

[16] L.E. Freed, G. Vunjak-Novakovic, R.J. Biron, D.B. Eagles, D.C. Lesnoy, S.K. Barlow, and R. Langer, "Biodegradable polymer scaffolds for tissue engineering", Biotechnology 12 (7), 689-693 (1994)

[17] K.W. Leong, H. Lo, and M.S. Ponticiello, "Fabrication of controlled release biodegradable foams by phase separation", Tissue Engineering 1 (1), 15-28 (1995).

[18] R.C. Thomson, M.J. Yaszemski, J.M. Powers, and A.G. Mikos, "Fabrication of biodegradable polymer scaffolds to engineering trabecular bone", J. Biomater. Sci. Polym. Ed. 7 (1), 23-38 (1996).

[19] W. Yee Yeonga, Ch. Kai Chuaa, K.-Fai Leonga, and M. Chandrasekaran, "Rapid prototyping in tissue engineering: challenges and potential", Trends in Biotechnology 22 (12), 643652 (2004)

[20] W. Hea, Z.W. Mab, T. Yonga, W.E. Teoc, and Seeram Ramakrishna, "Fabrication of collagen-coated biodegradable polymer nanofiber mesh and its potential for endothelial cells growth", Biomaterials 26 (36), 7606-7615 (2005).

[21] R.E. Unger, M. Wolfa, K. Petersa, A. Mottab, C. Migliaresib, and C. James Kirkpatrick, "Growth of human cells on a non-woven silk fibroin net: a potential for use in tissue engineering”, Biomaterials 25 (6), 1069-1075 (2004).

[22] M. Remy-Zolghadri, J. Laganiere, J.F. Oligny, L. Germain, and F.A. Auger, "Endothelium properties of a tissue-engineered blood vessel for small-diameter vascular reconstruction", J. Vasc. Surg. 39 (3), 613-620 (2004).

[23] K. Kottke-Marchant, A.A. Veenstra, and R.E. Marchant, "Human endothelial cell growth and coagulant function varies with respect to interfacial properties of polymeric substrates", J. Biomed. Mater. Res. 30 (2), 209-218 (1996).

[24] C.J. Kirkpatrick, M. Otto, T. van Kooten, V. Krump, J. Kriegsmann, and F. Bittinger, "Endothelial cell cultures as a tool in biomaterial research", J. Materials Science: Materials in Medicine 10, 589-594 (1999).

[25] M.J. Dalby, M.O. Riehlea, H. Johnstoneb, S. Affrossmanb, and A.S.G. Curtis, "In vitro reaction of endothelial cells to polymer demixed nanotopography", Biomaterials 23 (14), 2945-2954 (2002). 